\title{
Impacts of Learning Management System on Learner Autonomy in EFL Learning
}

\author{
Tin Tan Dang \& Margaret Robertson \\ Faculty of Education, La Trobe University
}

This study was funded by La Trobe University Postgraduate Research Scholarship and Endeavour International Postgraduate Research Scholarship.

\begin{abstract}
The integration of interactive online communication into different educational settings has been widely researched since the emergence of Web 2.0 technology. It has been particularly identified to give EFL students more opportunities to express ideas, enhance their engagement in learning activities and promote their confidence during virtual interactions. These benefits coincide with attributes of a learning environment that can foster learner autonomy. Therefore, this paper reports on an investigation into the impacts of the employment of a web 2.0 Learning Management System (LMS) in an EFL course. Data extracted from individual interviews with four undergraduate students in a Vietnamese university was analyzed to illustrate possible effects of LMS in students' ability to initiate, monitor and evaluate their learning process. The presentation continues with a discussion on the cyclic relationship among these three capabilities. It also addresses the local students' perspective on socializing and academic activities as well as the relationship between them in the socio-cultural context of Vietnam. It then concludes with implications for EFL teaching practices with the adoption of LMS and puts forward suggestions for further research.
\end{abstract}

Keywords: ICT, LMS, web 2.0, socio-cultural theory, Vietnamese EFL, learner autonomy.

\section{Introduction}

Apart from non-interactive technology development such as radio, video players, and standalone software packages, interactive communications via web 2.0 have revolutionized human daily communicative habits. Email, instant messenger, discussion board, and social networking have been possibly and potentially seen in many aspects of our life. Taking these into consideration, educators have been paying a lot of attention to investigating possible effects of this emerging technology on young learners to help them learn better in the new dynamic environment. In second language learning, various attempts and initiatives have been developed and documented in different learning settings, especially in developed countries. However, in the context of Vietnam, where internet broadband has only recently become very popular and affordable, the employment of web 2.0 in EFL training has been very limited. Therefore, this paper reports on a study investigating Vietnamese EFL students' reflection on a web 2.0 LMS (Note 1) that they worked with during a course. The main discussion focused on the local students' autonomous learning behaviors in relation to their cultural values in online learning.

\section{Literature Review}

\subsection{Benefits of Online Technology in EFL Education}

There have been extensive discussions on the usage of online technology or computer mediated communication (CMC) in language education. Investigations on the latest communication channels such as weblog (e. g., Downes, 2004; Mortensen, 2008), discussion board (e. g., Bhappu, Ebner, Kaufman, \& Welsh, 2009), social network (Boyd \& Ellison, 2007; Ellison, Steinfield, \& Lampe, 2007), and instant messenger (e. g., Jacobs, 2008; Lewis \& Fabos, 2005) to name a few have been described. As a result, CMC has been indicated to contribute to students' linguistic development mediation (Darhower, 2002), help students identify language genres (Lam, 2004), increase their success in using the target language (Hanna \& de Nooy, 2003), and provide more opportunities for negotiations, collaborations, interactions and communications (Jonassen, 2004; Kitade, 2000, 2006; Leahy, 2008).

As interlocutors involved in both synchronous and asynchronous CMC are bound by their real life identities in certain socio-cultural contexts and virtual characteristics of the online space, research in CMC has recently shifted its focus to the interactions between learners and the technology with an emphasis on socio-cultural aspects, rather than on a purely technological perspective. In other words, various CMC-mediated attributes in relation to learners' contexts have been targeted (Thomas, 2008). Studies such as Darhowers (2002), Lee (2005), Leahy (2008), and Hull \& Saxon (2009) have successfully adopted socio-cultural theory (SCT) to investigate 
various learning variables in CMC integrated learning environments. They also argue for further explorations in particular contexts as one method cannot fit all.

\subsection{Learner Autonomy in EFL Education}

Learner autonomy has been considered as one of the ultimate goals in contemporary EFL education, "an idea that researchers and teachers ignore at their peril" (Benson, 2009, p. 14). Historically, learner autonomy was defined as an "ability to take charge of one's own learning" (Holec, 1981, p. 3) and manifested by the ability to initiate, monitor, and evaluate learning processes (Little, 2003). Learner autonomy has been perceived by four groups of perspectives, namely psychological, technical, socio-cultural, and political-critical (Benson, 1997, 2006; Healy, 2007; Oxford, 2003). The technical perspective values attributes from the learning environment, and the psychological perspective values personal attributes from the learners. Meanwhile, the socio-cultural perspective lays the emphasis on the interactions between learners and their environment, and the political-critical perspective focuses on learners' access, control, power and ideology in their community.

Given the development history of over four decades and the notoriously complicated nature of this construct (Little, 2003), learner autonomy has been diversely interpreted in different contexts (Dang, 2010). Various versions of learner autonomy such as personal autonomy (Young, 1986), divergence and convergence (Ribe, 2003), weak and strong (Smith, 2003), and narrow and broad (Kumaravadivelu, 2003) have been proposed and discussed; however, it has been significantly argued in contemporary literature that this multifaceted capacity needs to be localized and addressed in particular social contexts (Smith \& Ushioda, 2009). This social turn is, therefore, allocated appropriately in the notion of SCT and provides important theoretical foundations to research in this area (Toohey, 2007).

\subsection{Learner Autonomy and Online Technology in EFL Education}

Looking across research in CMC, computer-assisted language learning (CALL), and learner autonomy, one can see a close relationship between them via their contributions to learners' benefits. Motteram (1997) and Benson (2001) have argued that the association between the two was created by the multiple resources, options, negotiations and interactions produced by educational technology that in turn facilitate learner autonomy. As indicated in Figure 1, appropriate CMC integration in EFL education has been often identified to foster reflective learning (e. g., Chang \& Sun, 2009), enhance learning engagement (e. g., Sinclair, 2009), and facilitate interactive collaborations (e. g., Leahy, 2008; Warschauer, Turbee, \& Roberts, 1996); and these are prerequisites for the development of learner autonomy.

In addition, the presentation of the theoretical framework employed in many CMC and learner autonomy studies in the previous sections is SCT. As documented by Thorne (2008), Pemberton and his colleagues (Pemberton, Toogood, \& Barfield, 2009), this theory of Vigotsky becomes significantly useful for research in these two areas as it helps explain mediated attributes of human activities. Every individual behavior is regulated by an internalization process of what he/she historically knows and can create. Therefore, both students' CMC activity participation and their construction of learner autonomy capacity can be nurtured and explained with supports from their revolutionary potentials and communal practices (Sawchuk, Duarte, \& Elhammoumi, 2006). This linkage and argument have allowed the current study to employ SCT in its investigation and interpretation (c.f., Dang, 2010). The local socio-cultural values were particularly drawn on to understand students' online behaviors.

\section{Study Design (Note 2)}

Given significant attention to the socially-situated nature of learner autonomy, the first phase of this project was to investigate the characteristics of learner autonomy that Vietnamese EFL undergraduate students perceive. It employed a Likert scale survey of 62 items and collected quantitative data from 562 undergraduate students in four universities across Vietnam. As a result, the factor analysis and internal consistency tests from this sample generated five dimensions of learner autonomy. One of these was Using Information and Communication Technology (ICT) in learning processes. Taking this into account, this study was designed to investigate how students' use of CMC fostered their learner autonomy capacity. It particularly looked at the extent to which the interactions between Vietnamese EFL undergraduate students and a web 2.0 LMS, an open source Moodle site, during a 16 week course contribute to the manifestations of ability to initiate, monitor, and evaluate learning processes.

Participating in this Listening - Speaking course were over 240 EFL first year students in a Vietnamese university. They ranged from 18 to 24 years of age, and had not worked with LMS prior to this course. These students were divided into five groups, taught by three lecturers. The LMS component accounted for $15 \%$ of the 
total course evaluation in the first four groups and was totally optional in the fifth group. By the end of the course, twelve students responded to an interview invitation sent by the researcher. None of them was from the fifth group (c.f., Dang \& Robertson, 2009). Interview extracts from the first four students alphabetically were selected to report in this paper.

This study employed the retrospective method (Cohen, Manion, \& Morrison, 2007), asking each participant to talk about the experience that they had when working with the LMS. The individual semi-structured interview provided questions to elicit students' behaviors that were related to their ability to (i) initiate, (ii) monitor, and (iii) evaluate learning processes. The interview guidelines were principally developed from several previous studies (such as Martinez, 2008; Smith \& Erdogan, 2008) with serious considerations paid to the participants' socio-cultural context. It included questions such as (i) Does any LMS activity give you any opportunity to trigger your learning such as providing you some materials, initiating some communication, or activating your curiosity about a topic? Any example? (ii) Does any LMS activity help you monitor your work such as reminding you of some work or changing your learning habits? Any example? (iii) Does any LMS activity help you evaluate your learning such as allowing you to review and your friends to evaluate your work, or giving you opportunities to compare your work with others'? Any example? All interviews were done in Vietnamese and transcribed for analysis.

The LMS was hosted in the city where the university was located to facilitate loading speed. It was password-protected and integrated with different modules and plug-ins necessary for the course such as Voice of America and British Broadcasting Corporation radio channels for listening practice, OU blog and chat room for communication, and voice message posting for speaking practice. The LMS activities started from week three and finished by the end of the course. Each LMS class consisted of six categories, namely course administration, sharing learning experience, improving listening skills, improving speaking skills, group presentations and short test and quizzes. Each category included subcategories, depending on the lecturers.

The sections in the LMS were pedagogically designed to create a virtual space for individual reflections and collaborative tasks among students themselves and with the lecturers. They were technically based on three aspects of web 2.0, namely Wiki writing collaboration, synchronous chat and asynchronous discussion board. However, the wiki was not implemented by the lecturers; and the chat system was used very little by the participants. Therefore, only the discussion forum based technology is addressed in this report.

\section{Results}

\subsection{Ability to Initiate Learning Process}

The LMS component (Note 3) was reported to support students' initiating their learning, but it did not have the same level of effects on every student. Three of the four interviewees reported that they needed to go to their virtual classes very frequently because they would like to get updates from friends and teachers while one of them indicated that she visited the site only two or three times a week. This difference was due to students' general online habits which did not significantly change during the course, given a small portion of the LMS component in only one course across the whole semester.

However, their level of participation in the LMS activities increased as the course went on. As more communication and information were generated toward the end of the course, students became more engaged in their online activities. As a result, a community was gradually developed (c.f. Jeon-Ellis, Debski, \& Wigglesworth, 2005). Student N said:

"At first, I only wanted to see if there was anything new out there. However, I realized that there were so many postings, and that made me log in the class more often."

This was reinforced by student $\mathrm{M}$, who said:

"I often go to my virtual class to see if there was any update [...]. I found out that there were many postings that received many replies. Therefore, I came to them, read them, and posted replies, asking for further details."

The resources and topics posted for discussion in the virtual classes also triggered students' learning processes. Two interview participants agreed that many postings encouraged them to look for more relevant information in other sources. For example, student $\mathrm{N}$ said:

"I often went to my friends' postings and the links that my teacher introduced. I also read my friends' blogs and comments. [...] I was particularly interested in blog entries [...] and read them every day."

This was further illustrated by student M's comments: 
"My teacher posted a video clip about a disabled man whose name was Nick. After watching it, I went to Youtube to search for more clips about him and downloaded them into my computer."

However, the other two suggested that those online discussion threads did not trigger their learning process much because they did not find any topic which was interesting enough. If they had seen an interesting topic, they would have looked for further details. Student A said:

"That [topics that can trigger further research] has not happened to me yet. However, if there is any topic appealing to me, I'll certainly have more investigations on it."

This is similar to student D's comment: “...If it were a good song, I would probably study more about it."

It is important to note that replies to postings could trigger students' various reading directions and communicative engagements. These were clearly indicated in student A's comment as below

"When I got a comment, even negative or positive, I tried to see if I liked the commentator by his/her expressions. If I felt I liked him/her, I'd try to understand more about him/her. I'd try to read all of his responses to other postings elsewhere."

\subsection{Ability to Monitor Learning Process}

One student reported that the LMS component made her spend more time on the course but three others did not think so. Further analyses indicated that this difference was caused mainly by their interpretation of learning. Student A was very aware of her time in the LMS activities because she considered it part of her learning and accumulative efforts which would be counted for the course evaluation. Therefore, she thought that it took more time from her. She said:

"I saved more time for this course. I thought that my teacher checked students' online records for course evaluation, and I was afraid of that. Thus, I went to the LMS more frequently."

In contrast, the other three students considered visiting LMS as part of their daily routines. Even without the LMS, they went to different websites every day. Therefore, they just included the LMS into their daily internet activities, and did not recognize that they were spending more time on the course. In this case, the LMS was naturally integrated into students' general internet life.

The LMS was also reported to have effects on students' implementing and regulating learning processes. They had opportunities to choose what postings to read, what activities to take part in, and what threads to respond to. Student N was particularly interested in the Global Blog; while student D found the Listening Game useful but the Listening Practice. In addition, they often selected to take part in recent and appealing thread titles with many contributors. If a thread was posted a few days before with a regular title and did not attract any comments, it was not considered to be worth reading by the students. They also asserted that working with the LMS encouraged them to keep track of their online activities and increase their learning engagement. For example, student A said:

"I logged in the site and checked if there were any responses to my postings. If yes, I would read them to see what the responders thought of me. I then compared these responses to those posted by these responders in other postings."

Although these CMC exchanges were not always content-rich ("only one or two lines" - student N), they contributed to the construction and maintenance of students' online conversations and blurred the gap between school and social life. They also increased students' interest in the course (c.f. Fujiike, 2004; Khalsa, Maloney-Krichmar, \& Peyton, 2007). Student N said:

"The LMS made the course more interesting. I normally had regular contacts with only some friends and did not talk to many others. However, I could know a lot about them when reading their postings on the LMS. I could know what they often wrote about, what their thoughts were, and how their lives were. These would help me understand them more easily."

The LMS was also reported to help students know more about their friends' personalities and music genre (Student A and Student D respectively). These indicated that LMS was seen as an environment for socializing and understanding others' personal life. The academic and social domains were intertwined in students' behaviors.

\subsection{Ability to Evaluate Learning Process}

All of the interviewees agreed that the CMC activities gave them opportunities to evaluate the work of themselves and their friends. They also allowed them to understand about their friends' level more accurately 
and the general level of the cohort thoroughly. Student $\mathrm{M}$ and $\mathrm{D}$ reported that they often checked if their peers made any mistakes in their postings and learned from them. Meanwhile, student A always compared her postings with the others'. In contrast, student $\mathrm{N}$ said that she never attempted to do such a comparison. She only tried to learn from her peers' writing styles and word usages. Nevertheless, they all acknowledged that there were some students who did not talk much in class but placed a lot of postings in the LMS (c.f. Burgess, 2006), and that gave them a different evaluation on these students.

Students' judgments on postings were often involved in critical negotiations. Although many mistakes in a posting could trigger negative effects on the reader, they were not necessarily used for assessment because the reader may think that it was simply caused by carelessness.

"There were probably mistakes in a posting but it was because they were careless and did not check it properly. However, too many mistakes can make me annoyed."

\section{Student D}

This student also indicated that there were those who did not have many postings on the LMS and go online regularly but made good achievements in class. Therefore, using the LMS participation for evaluation purposes was not always accurate. In addition, if there were any evaluative comments on a posting, they needed to be addressed by the posting writer. That would facilitate better understanding and could produce a more precise evaluation.

\section{Discussion}

The LMS employed in the study was indicated to direct students' attention to a local CMC environment for idea exchanges and negotiations, but it did not probably increase students' online habit as a whole. Those who went to the internet everyday came to the LMS every day, and those who went online less frequently visited the LMS less often. In other words, being accounted for $10 \%$ of the course evaluation and used in only an one-semester course in the whole program, LMS activities did not basically modify students' online habits quantitatively. What they could do was to make the LMS become one of students' often-visited sites and/or replacing some of their favorite sites. These showed that local students' online habit was principally shaped by social factors rather than academic factors. Therefore, online interactions are probably associated with purposes other than academic. Further attempts of ICT applications in academic environments may need to address this issue.

The quality of contributed content was reported to be the most important factor that could draw participants' attention and facilitate communication. Although the mandate for LMS participation, course assessment, and individual learning styles and preferences may have triggered certain incentives for LMS engagement, they were not the main factor for maintaining that engagement process. When logged on to a computer, students were often involved in multiple sessions from different applications. Therefore, the ones that were judged to be more interesting and important would receive more attention from students. Student D said that she always worked with different tabs at the same time; therefore, comparative evaluations among these contents automatically came, and that redirected her engagement to the content that she found she was comfortable with.

As the LMS in this study was designed for out-of-class activities only, it challenged the students' ability to personalize their learning activities effectively and lecturers' ability to facilitate appropriate content and conversations. Because the LMS provided students with an always-on communication channel which they could take part in anywhere, they could flexibly choose to integrate it into their daily plan at any comfortable level which may not in turn be optimal for their learning. This led to one of the most important issues of lecturers' role as proposed in previous studies (e.g., Son, 2007; Stepp-Greany, 2002). Therefore, it should be the lecturers' responsibility to provide adequate facilitation for suitable knowledge generation which could keep students stay with the LMS, especially in a highly competitive information environment like internet.

Given the fact that most of the course participants were "digital natives" (Prensky, 2001), they did not attempt to explicitly differentiate between socializing and studying activities in their online world. As illustrated in Figure 2, the relationship between two types of activities was differently perceived in online and offline contexts. Accordingly, on one hand, students could apply the monitoring skills that they already possessed with the social applications to their online academic component when it was introduced by the course. On the other hand, the content and foci of the academic component could spread out and assimilate into the social applications. These processes and skill transference would hopefully enable students to achieve better outcomes.

That different levels of evaluation were reported also contributed to the appropriateness of this technology-based learner autonomy promoting practice. As the function of rating postings was reserved for the lecturers only, students had to leave comments on each thread and that generated a conversation for those active interlocutors 
and other lurkers. These negotiations allowed them to evaluate/re-evaluate and reflect/re-reflect on the contents, extended-discussions, and skills of their peers and themselves (c.f., Horváth, 2005). It was necessary to note that these digital natives tended to tolerate e-mistakes well and be aware of other reasons for possible performance inhibition. They valued e-performance but understood that it was not the only environment to demonstrate capabilities. Therefore, judgments which were based solely on virtual space would be superficial.

Similar to the quantitative data collected from the first phase of this project, the processes of initiating, monitoring and evaluating learning activities were reported to be intertwined and cyclic. For example, student A and D replied to (initiating) comments to negotiate with their peers about the evaluation of a postings (evaluating) and read these peers' comments in other postings for comparison (monitoring). These processes then kept happening continuously, even when they were physically away from the LMS. As a result, the execution of these processes was overlapping. When an action was implemented, it may have attributes of two or three processes. In another word, one process can be regulated by the other two capacities. These interwoven connections were diagrammatically illustrated in Figure 3.

Illustrated through students' interactive behaviors with the LMS were the socio-cultural values that the virtual environment added to students' real life. With their participation in the LMS both naturally and mandatorily, students improved their understanding about the others and themselves in others' mind. The online environment was used as a compensation for the offline society where students were under time constraints and movement limitations and could not directly get in touch with all of their friends as they wished to. The LMS also contributed to shape students' social relationship and identity. They started to negotiate some friendship with anyone who appeared to be related to them by reading his/her comments and postings all over the LMS. They tried to see if they liked him/her, what he/she thought about them, and what he/she thought about the others.

It is the scope of the study that limits its investigations in some aspects. First, it was the minority population of males in the EFL program that did not allow any of their voice to be included in the analysis. Second, the interview for data generation was totally voluntary; therefore, it could reflect perspectives of those who would like to express their ideas only. Those who were culturally timid and passive in both learning and social life may have not been confident enough to respond to the email invitation from the researcher. Third, the paper reports on the data generated only from four among twelve interviewees; hence, there probably remain other views which were not included. Nevertheless, the sampling reflects the nature of the research population that can be used to depict the manifestations of learner autonomy in the local context.

\section{Conclusion}

The paper started with several general benefits that CMC technology potentially contributed to the development of learner autonomy. Reporting on the data collected in the context of EFL training in Vietnamese higher education, it demonstrated the interwoven and cyclical relationships of the three learner autonomy abilities. It also addressed differences in the local students' perspectives on socializing and academic activities in online and offline contexts. In addition, it discussed the influence of social and academic factors on shaping students' e-habits as well as the socio-cultural values that the online learning dimensions contributed to students' offline social life. These have suggested that EFL educators need to take advantage of students' social e-habits for educational purposes and employ effective facilitations to keep them engaged in the course conversations but avoid dominating those contexts. It is also necessary for empirical research to document the development and manifestation of learner autonomy capacity in both socializing and academic activities and the relationship between them in the virtual world.

\section{References}

Benson, P. (1997). The philosophy and politics of learner autonomy. In P. Benson \& P. Voller (Eds.), Autonomy and independence in language learning (pp. 18-34). London: Longman.

Benson, P. (2001). Teaching and researching autonomy in language learning. London: Longman.

Benson, P. (2006). Autonomy in language teaching and learning. State-of-the-art Article. Language Teaching, 40(1), 21-40.

Benson, P. (2009). Making sense of autonomy in language learning. In S. Toogood, R. Pemberton \& A. Barfield (Eds.), Maintaining control: Autonomy and language learning (pp. 13-26). Hong Kong: Hong Kong University Press.

Bhappu, A. D., Ebner, N., Kaufman, S., \& Welsh, N. (2009). Online communication technology and relational development. In C. Honeyman, J. Coben \& G. D. Palo (Eds.), Rethinking Negotiation Teaching: Innovations For Context And Culture (pp. 239-249). Saint Paul: DRI Press. 
Boyd, D. M., \& Ellison, N. B. (2007). Social network sites: Definition, history, and scholarship. Journal of Computer-Mediated Communication, 13(1). Retrieved from $\mathrm{http}: / / \mathrm{jcmc}$.indiana.edu/vol13/issue1/boyd.ellison.html

Burgess, J. (2006). Blogging to learn, Learning to blog. In A. Bruns \& J. Jacobs (Eds.), Uses of blogs (Vol. Digital formations, pp. 105-114). New York: Peter Lang.

Chang, W.-L., \& Sun, Y.-C. (2009). Scaffolding and web concordancers as support for language learning. Computer Assisted Language Learning, 22(4), 283 - 302.

Cohen, L., Manion, L., \& Morrison, K. (2007). Research methods in education (6th ed.). London; New York: Routledge.

Dang, T. T., \& Robertson, M. (2009). Online Communications: Students' Habits and Community Formation. Paper presented at the AARE 2009 Conference: Inspiring Innovative Research in Education, Canberra.

Dang, T. T. (2010). Learner autonomy in EFL studies in Vietnam: A discussion from sociocultural perspective. English Language Teaching, 3(2), 3-9.

Darhower, M. (2002). Interactional features of synchronous computer-mediated communication in the intermediate L2 class: A sociocultural case study. CALICO Journal, 12(3), 249-277.

Downes, S. (2004). Educational blogging. EDUCAUSE Review, 39(5), 14-26.

Ellison, N. B., Steinfield, C., \& Lampe, C. (2007). The benefits of Facebook "friends:" Social capital and college students' use of online social network sites. Journal of Computer-Mediated Communication, 12(4).

Fujiike, T. (2004). Collaborative Interaction in EFL Web-Based Debates: How Do Learners Develop Socially Constructed Knowledge? CALL-EJ Online, 5(2).

Hanna, B., \& de Nooy, J. (2003). A funny thing happened on the way to the forum: Electronic discussion and foreign language learning. Language Learning and Technology, 7(1), 71-85.

Healy, D. (2007). Theory and research: autonomy and language learning. In J. Egbert \& E. Hanson-Smith (Eds.), CALL environments: research, practice, and critical issues (2nd ed., pp. 377-388). Alexandria, Va.: Teachers of English to Speakers of Other Languages.

Holec, H. (1981). Autonomy in foreign language learning. Oxford: Pergamon.

Horváth, I. (2005). The cognitive components of autonomous learning in postgraduate interpreter training. Paper presented at the 2nd Independent Learning Association Oceania Conference. Retrieved 10-10-2008, from http://independentlearning.org/ILA/ila05/ila05_papers.htm

Hull, D. M., \& Saxon, T. F. (2009). Negotiation of meaning and co-construction of knowledge: An experimental analysis of asynchronous online instruction. Computers \& Education, 52(3), 624-639.

Jacobs, G. E. (2008). People, purposes, and practice: Insights from cross-disciplinary research into instant messaging. In J. Coiro, M. Knobel, C. Lankshear \& D. J. Leu (Eds.), Handbook of research on new literacies (pp. 467-490). New York: Lawrence Erlbaum Associates/Taylor \& Francis Group.

Jeon-Ellis, G., Debski, R., \& Wigglesworth, G. (2005). Oral interaction around computers in the project-oriented call classroom. Language, Learning \& Technology, 9(3), 121-145.

Jonassen, D. H. (Ed.). (2004). Handbook of Research on Educational Communications and Technology (2 ed.). Mahwah, NJ: Lawrence Erlbaum Associates.

Khalsa, D. K., Maloney-Krichmar, D., \& Peyton, J. K. (2007). Theory and research: Interactions via computers. In J. Egbert \& E. Hanson-Smith (Eds.), CALL environments : research, practice, and critical issues (2nd ed., pp. 19-28). Alexandria, Va.: Teachers of English to Speakers of Other Languages.

Kitade, K. (2000). L2 learners discourse and SLA theories in CMC: Collaborative interaction in Internet chat. Computer Assisted Language Learning, 13(2), 143-166.

Kitade, K. (2006). The negotiation model in asynchronous computer-mediated communication (CMC): Negotiation in task-based email exchanges. CALICO Journal, 23(2), 319-348.

Kumaravadivelu, B. (2003). Beyond methods: Macrostrategies for language teaching. New Haven: Yale University Press.

Lam, W. S. E. (2004). Second language socialization in a bilingual chat room. Language Learning and Technology, 8(3), 44-65. 
Leahy, C. (2008). Learner activities in a collaborative CALL task. Computer Assisted Language Learning, 21(3), $253-268$.

Lee, L. (2005). Using web-based instruction to promote active learning: Learners' perspectives. CALICO Journal, 23(1), 139-156.

Lewis, C. \& Fabos, B. (2005). Instant messaging,, literacies, and social identities. Reading Research Quarterly, 40(4), 470-501.

Little, D. (2003). Learner autonomy and second/foreign language learning. Guide to Good Practice. Retrieved from http://www.llas.ac.uk/resources/gpg/1409

Martinez, H. (2008). The subjective theories of student teachers: Implication for teacher education and research on learner autonomy. In T. Lamb \& H. Reinders (Eds.), Learner and teacher autonomy: concepts, realities, and responses (pp. 103-124). Amsterdam; Philadelphia: John Benjamins Pub. Co.

Mortensen, T. E. (2008). Of a divided mind: Weblog literacy. In J. Coiro, M. Knobel, C. Lankshear \& D. J. Leu (Eds.), Handbook of research on new literacies (pp. 449-466). New York: Lawrence Erlbaum Associates/Taylor \& Francis Group.

Motteram, G. (1997). Learner Autonomy and the Web. In V. Darleguy, A. Ding \& M. Svensson (Eds.), Educational Technology in Language Learning: Theoretical Considerations and Practical Applications (pp. 17-24). Lyons: INSA (National Institute of Applied Sciences).

Oxford, R. (2003). Toward a more systematic model of L2 learner autonomy. In D. Palfreyman \& R. Smith (Eds.), Learner autonomy across cultures: language education perspectives (pp. 75-91). New York: Palgrave Macmillan.

Pemberton, R., Toogood, S. \& Barfield, A. (Eds.). (2009). Maintaining Control: Autonomy and Language Learning. Hong Kong: Hong Kong University Press.

Prensky, M. (2001). Digital Natives, Digital Immigrants On the Horizon 9(5).

Ribe, R. (2003). Tramas in the foreign language classroom: autopoietic networks for learner growth. In D. Little, J. Ridley \& E.Ushioda (Eds.), Towards Autonomy in Foreign language Learning (pp. 11-28). Dublin: Authentik.

Sawchuk, P. H., Duarte, N. \& Elhammoumi, M. (2006). Critical perspectives on activity: Explorations across education, work, and everyday life. New York: Cambridge University Press.

Sinclair, B. (2009). The teacher as learner: Developing autonomy in an interactive learning environment. In R. Pemberton, S. Toogood \& A. Barfield (Eds.), Maintaining Control: Autonomy and Language Learning (pp. 175-198). Hong Kong: Hong Kong University Press.

Smith, R. (2003). Pedagogy for autonomy as (becoming-) appropriate methodology. In D. Palfreyman \& R. Smith (Eds.), Learner autonomy across cultures: language education perspectives (pp. 129-146). New York: Palgrave Macmillan.

Smith, R. \& Erdogan, S. (2008). Teacher-learner autonomy: Programme goals and student-teacher construct. In T. Lamb \& H. Reinders (Eds.), Learner and teacher autonomy: concepts, realities, and responses (pp. 83-102). Amsterdam; Philadelphia: John Benjamins Pub. Co.

Smith, R. \& Ushioda, E. (2009). 'Autonomy': under whose control? In R. Pemberton, S. Toogood \& A. Barfield (Eds.), Maintaining Control: Autonomy and Language Learning (pp. 241-253). Hong Kong: Hong Kong University Press.

Son, J.-B. (2007). Learner experiences in web-based language learning. Computer Assisted Language Learning, 20(1), 21 - 36.

Stepp-Greany, J. (2002). Student perceptions on language learning in a technological environment: Implications for the new millennium. Language, Learning \&amp; Technology, 6(1), 165.

Thomas, A. (2008). Community, culture, and citizenship in cyberspace. In J. Coiro, M. Knobel, C. Lankshear \& D. J. Leu (Eds.), Handbook of research on new literacies (pp. 671-697). New York: Lawrence Erlbaum Associates/Taylor \& Francis Group.

Thorne, S. L. (2008). Mediating Technologies and Second Language Learning. In J. Coiro, M. Knobel, C. Lankshear \& D. J. Leu (Eds.), Handbook of research on new literacies (pp. 142-447). New York: Lawrence Erlbaum Associates/Taylor \& Francis Group. 
Toohey, K. (2007). Conclusion: Autonomy/Agency through socio-cultural lenses. In A. Barfield \& S. H. Brown (Eds.), Reconstructing autonomy in language education: inquiry and innovation (pp. 231-242). Basingstoke: Palgrave Macmillan.

Warschauer, M., Turbee, L., \& Roberts, B. (1996). Computer learning networks and student empowerment. System, 24(1), 1-14.

Young, R. (1986). Personal autonomy: Beyond negative and positive liberty. London: Croom Helm.

\section{Notes}

Note 1. The LMS mentioned in this study is the one using web 2.0 technology.

Note 2. As this study is part of a larger research project, it employed a research design similar to the one presented in Dang \& Robertson (2009)

Note 3. As all the activities on the LMS in this study are CMC, CMC and LMS activities are used interchangeably in this paper.

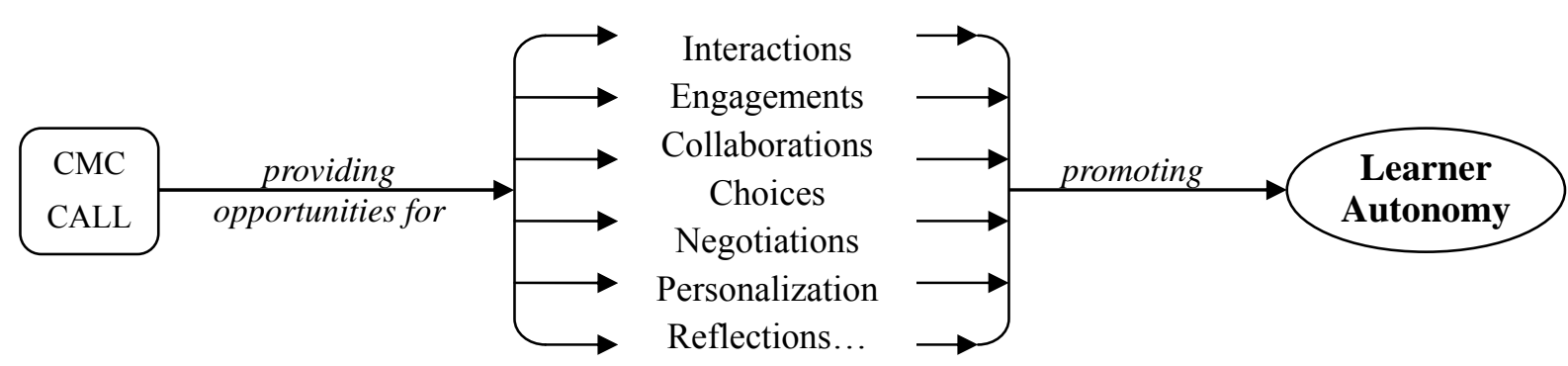

Figure 1. The relationship between CMC and learner autonomy in EFL education
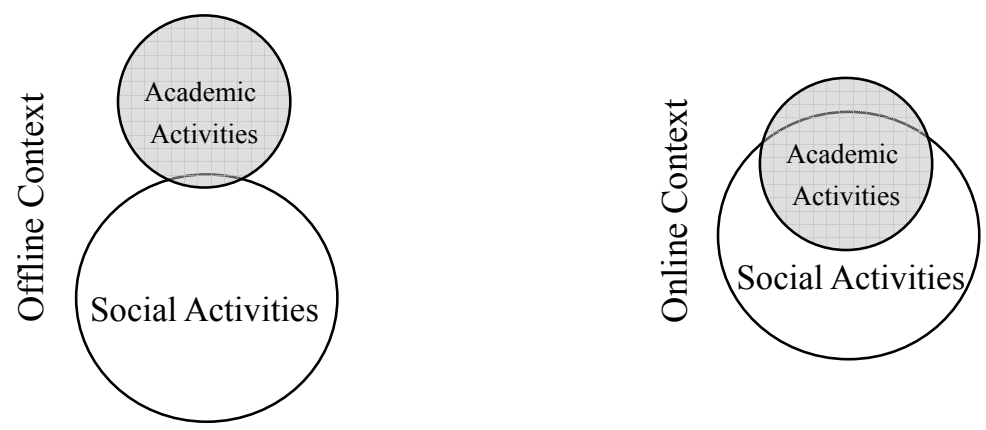

Figure 2. Students' perceived relationship between social and academic activities

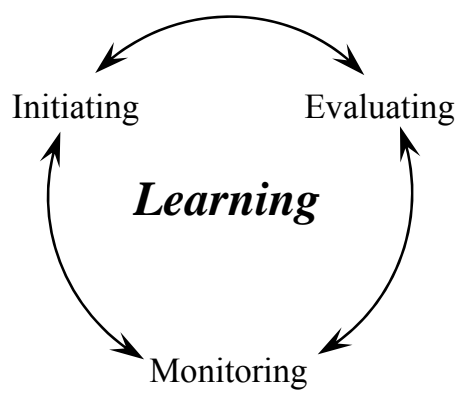

Figure 3. The cyclic relationship of the three intertwined processes of learner autonomy 